\title{
Ações e reações da escola diante de masculinidades hegemônicas e não hegemônicas: um olhar antropológico
}

RAIMUNDO NONATO FERREIRA DO NASCIMENTO

UNIVERSIDADE FEDERAL DO PLAUÍ (UFPI), TERESINA/PI, BRASIL

HTTPS://ORCID.ORG/OO00-0003-2667-7928

MARCOS PAULO MAGALHÄES DE FIGUEIREDO

UNIVERSIDADE FEDERAL DO PLAUÍ (UFPI), TERESINA/PI, BRASIL

HTTPS://ORCID.ORG/OOOO-OOOI-6872-5399

\section{Introdução}

"O tema da sexualidade está na 'ordem do dia' da escola", nos diz Helena Altmann, em texto publicado em 2001. Naquele período, segundo a autora, o assunto se fazia presente nos diversos espaços das instituições de ensino, nos debates, nas brincadeiras e permeava todo esse universo. A visibilidade resultava do fato de a sexualidade ter se constituído, segundo os Parâmetros Curriculares Nacionais (PCNs), como um tema transversal a ser trabalhado na e pela escola a partir de 1998.

Ora, se a temática 'corpo e sexualidade' tornou-se recorrente nas escolas brasileiras no início do século XXI, faz-se necessário ir além desse marco legal e questionar o porquê dessa inserção discursiva sobre sexo nessas instituições, bem como é prudente compreender o significado dessa abordagem no campo da educação formal e quais epistemologias guiariam esse debate. De acordo com Altmann (2001), a introdução do tema 'orientação sexual' como transversal demonstrava de forma cristalina o interesse do Estado pela sexualidade da população, porém o que não estava evidente eram as razões de o assunto ter se constituído em um importante foco de investimento político e excepcional instrumento de tecnologias de governo (Foucault, 2013). 
Seguindo nessa mesma linha de raciocínio, Cesar (2009) afirma que mesmo uma parcela da sociedade brasileira reconhecendo o lugar da sexualidade nos espaços escolares, o que trouxe essa discussão para a ordem do dia das escolas foram duas preocupações: o surgimento da epidemia de HIV no final dos anos 1980 e o reconhecimento da gravidez de jovens em idade escolar. Dessa forma, a autora sugere que a preocupação com sexualidade no âmbito educacional parece estar pautada em um viés higienista, em torno de uma ideia de prevenção, mas, que visava, sobretudo, ao controle e à domesticação dos corpos de jovens e crianças. Ainda segundo Cesar, a preocupação da instituição escolar com a sexualidade das crianças e jovens é bem antiga, remetendo-se ao século XIX, quando tais entidades estabeleceram um conjunto de regras sobre o corpo de seus estudantes. Recorrendo a Foucault (2014), a autora afirma que a escola, através de sua organização e normas, colocava o alunado em um contínuo sistema de vigilância.

A estrutura escolar, segundo Foucault (2014), foi pensada com o molde de outras instituições - como as fábricas ou o exército -, instaurando um conjunto de normas disciplinares, visando a maior produtividade, eficácia e homogeneização do corpo e do comportamento dos estudantes. Para isso, realizava-se uma fiscalização partilhada, por meio de uma "microfísica do poder" oriundo de um ponto central e que se capilariza através de diferentes atores e mecanismos regulatórios com a função de docilizar e padronizar os indivíduos no espaço escolar. A expectativa era de que sujeitos submetidos a rigorosas regras, sendo morosamente disciplinados a partir das normas institucionais, abandonassem suas construções anteriores, deixando-as fora daquelas paredes. Dessa forma, podemos afirmar que, na atualidade, a escola é vista como uma das instituições nas quais "se instalam mecanismos do dispositivo da sexualidade; através de tecnologias do sexo, os corpos dos estudantes podem ser controlados e administrados" (Altmann, 2001:4).

É, portanto, perceptível como a escola enquanto instituição procura efetuar um controle e uma docilização dos corpos dos estudantes de forma geral e, através de mecanismos de poder, fabrica corpos generificados, seja enquanto masculinos ou femininos. Entretanto, tal fabricação não acontece de maneira simplista. Encontram-se em jogo relações mais complexas, em que os estudantes não são sujeitos meramente inertes perante o exercício do poder sobre seus corpos. Trata-se, sim, de uma relação de força que acaba por propiciar a produção de corpos e concepções normatizadoras de gênero e sexualidade, em uma mecânica operacionalizada por relações de poder, mas também de resistência (Foucault, 2014; Louro, 2014).

Neste artigo, o corpo é o fragmento pelo qual visamos compreender o tensionamento entre instituição escolar e estudantes cujas masculinidades são consideradas abjetas no contexto pesquisado. Trata-se de um estudo em que os usos sociais e as performances da corporeidade serão o caminho de análise (Le Breton, 2006). O corpo aparece como um local privilegiado para análise das tensões entre a comunidade escolar e masculinidades não hegemônicas visto que: uma das formas pelas quais as performances de gênero são materializadas é através dele; as normas regulatórias calcadas em um ideal de masculinidade tido como salutar e aceitável têm o corpo como um dos seus principais alvos; de maneira ambivalente, é através dessa substância que os estudantes resistem às tentativas de regulação da 
sua corporeidade, posto que esse movimento de "correção" da masculinidade acontece principalmente sobre a performance corporal (Le Breton, 2006; Butler, 2000).

Especificamente entre garotos, as violências no âmbito escolar são constituintes importantes da cristalização de um certo tipo de masculinidade. Os meninos são ensinados através da violência e/ou bullying que masculinidade performar (Pascoe, 2018). Nesse sentido, concordamos com Reyes (2004) quando aponta a masculinidade como uma construção cultural e histórica, que se encontra rodeada de grande quantidade de elementos simbólicos e imaginários, sendo muitas vezes tomada com tanta naturalização que justifica certos comportamentos e atitudes, sem nos permitir uma imagem completa do que chamamos 'masculino'. No entanto,

é importante frisar que o fato de nos referirmos ao gênero, e em particular à masculinidade, como construída histórica e culturalmente e, portanto, assumindo características diferenciadas nas sociedades humanas, não afasta o suporte teórico do patriarcado, mas permite perceber que sua valorização diferenciada nas sociedades humanas torna seu entendimento mais complexo e, portanto, não pode ser explicado apenas como uma bipartição social em que um dos gêneros (o masculino neste caso) domina o outro (Reyes, 2004:103, tradução nossa).

Longe de uma concepção única de masculinidade, os estudos de gênero vêm se flexionando ao expor um leque de formas do ser masculino, afastando-se - ou não - da masculinidade fundamentada em uma dita virilidade. Assim, o conceito aqui trabalhado tem como base as concepções de masculinidade hegemônica e masculinidades subalternas, conforme Connell (1995; 2016), Connell \& Messerschimdt (2013) e Kimmel (1998). Portanto, nos ajudará a compreender como a escola, em seus discursos normatizadores, contribui com os processos de elaboração e afirmação das masculinidades hegemônicas nesse ambiente e como influencia os processos de construção dos corpos dos indivíduos, ou melhor, de suas identidades. Tencionamos também perceber como as concepções cristalizadas de uma masculinidade hegemônica produzida na e pela comunidade escolar, em seus diferentes níveis, destoam da realidade discente, marcada pela diversidade sexual e de gênero.

Para tanto, utilizaremos dados coletados durante a realização de um Estágio Supervisionado em Ciências Sociais ${ }^{1}$, com alunos de Ensino Médio em uma escola pública da rede estadual de Teresina (PI). Enquanto estratégia metodológica, optamos por uma abordagem qualitativa, tendo em vista nossa inserção no cotidiano da escola. Durante esse período - doravante denominado "trabalho de campo" - mantivemos contato frequente com os alunos e professores e, de forma mais direta, com a docente de Sociologia e Filosofia, também tutora do referido estágio supervisionado.

1 Os dados apresentados são oriundos da realização de duas atividades: a) Projeto de pesquisa cadastrado no Programa de Bolsas de Incentivo às Atividades Multiculturais e Acadêmicas, da Universidade Federal do Piauí (UFPI), coordenado pelo professor Raimundo Nonato, no qual Marcos (à época, aluno da graduação) atuava como pesquisador voluntário e b) da inserção dos dois autores na escola como estagiários, em atividades que ocorreram simultaneamente. Esclarecemos que, no período da investigação, o primeiro autor, além de coordenar o projeto a no qual o segundo era pesquisador voluntário, estava concluindo um curso de Licenciatura em Ciências Sociais pela Universidade Luterana do Brasil, modalidade à distância e, em virtude disso, naquele momento realizava o estágio supervisionado. Tal situação proporcionou a junção das duas atividades, pesquisa e estágio supervisionado, por parte dos dois autores. Assim, os dados aqui apresentados foram coletados por meio de visitas efetuadas, em média, de duas a três vezes por ambos. 
Era comum que conversássemos com alguns discentes na hora do recreio ou em momentos de lazer durante as horas de vacância das aulas. Umas das primeiras atividades de um estágio supervisionado é a observação e caracterização do espaço educacional. Nesse sentido, utilizamos o aporte teórico da Antropologia para realizar a observação participante, na qual buscamos apreender as concepções de masculinidade, bem como as relações de poder, através da percepção dos estudantes, professores e outros membros da comunidade escolar.

A observação no cotidiano escolar permitiu uma coleta espontânea das narrativas e dos acontecimentos ali experienciados, permitindo-nos captar as pequenas nuances das ações e falas dos sujeitos constituintes dessa comunidade. Contudo, temos a consciência de que nossa presença poderia inibir ou desinibir professores e alunos de se comportarem usualmente, pois fazer pesquisa no dia a dia implica levar em consideração que a atuação do pesquisador é parte integrante dela, pois ao mesmo tempo em que estamos analisando os acontecimentos daquele contexto, também estamos nele inseridos (Ferraço, 2007; Stecanela, 2009).

$\mathrm{O}$ artigo está organizado em quatro partes. A primeira e a segunda intencionam contextualizar a escola onde a pesquisa foi realizada, bem como realizar um debate sobre sexualidade e o lugar das diferenças nesse espaço. Na terceira e na quarta parte, será trabalhado o conceito de masculinidades e das formas de ser masculino, a partir de Connell (1995; 2016), Connell \& Messerschmidt (2013) e Kimmel (1998), assim como será feita a problematização a respeito dos acontecimentos em campo. Isso inclui a postura da comunidade escolar diante das práticas de masculinidades dissidentes e como se opera o discurso normalizador sobre esses corpos.

\section{Conhecendo o lócus da pesquisa: um olhar antropológico sobre a escola}

O lócus desta investigação é uma escola pública estadual, localizada em um bairro considerado o reduto da classe média da cidade de Teresina (PI). A instituição está em funcionamento desde o ano de 1972, quando iniciou suas atividades com a oferta do Ensino Fundamental, antigo Primeiro Grau. Com o passar dos anos e as mudanças advindas do próprio sistema educativo, passou a oferecer, também, o Ensino Médio. Nos dias atuais, conta também com Educação de Jovens a Adultos (EJA).

Apesar da localização privilegiada - um bairro que abriga vasto comércio, incluindo restaurantes, bares de renome e até grandes casas noturnas, estabelecimentos todos voltados para a classe média teresinense -, o público-alvo da escola é majoritariamente formado por jovens e adolescentes negros das classes mais baixas, vindos das periferias da cidade, dentre os quais grande parte está inserida no mercado de trabalho formal e/ou informal. Essa constatação se deu durante o trabalho de campo, a partir de nossa interação com os alunos e confirmou-se pela gestora da escola em uma entrevista.

Em termos de estrutura física, a instituição possui 12 salas de aula, para contemplar 27 turmas nos turnos matutino (11), vespertino (09) e noturno $(07)^{2}$. A escola ainda conta com sala da direção,

2 Os dados são referentes ao ano de 2017, obtidos durante a pesquisa de campo na escola. 
secretaria, cantina, dois conjuntos de banheiros para os alunos, sendo um masculino e outro feminino, dois banheiros para os funcionários da escola, espaço para o laboratório de Ciências, biblioteca, laboratório de informática, depósito, pátio e uma área aberta. Ainda em termos de estrutura, constatamos que todas as salas de aulas são climatizadas, embora nem sempre os aparelhos de ar-condicionado deem conta de manter uma temperatura agradável, principalmente no turno vespertino durante os quatro últimos meses do ano, pois, além do calor da época, as salas são abarrotadas com alunos e alunas. Aqui é válido mencionar que, no período da pesquisa, a escola havia passado por uma pequena reforma, visando uma melhoria no espaço para o atendimento dos estudantes.

O corpo discente atendido, bastante diversificado tanto do ponto de vista social quanto religioso e cultural, é de aproximadamente 1.200 alunos, divididos nos três turnos: matutino, vespertino e noturno. No matutino e vespertino funciona o Ensino Médio Regular, enquanto pela noite se realizam as atividades da Educação de Jovens e Adultos (EJA). Para atender a essa demanda, a escola conta com o apoio de um corpo de funcionários composto por 24 profissionais que atuam na parte burocrática e 46 professores das diversas áreas do conhecimento. As salas de aula sempre estavam lotadas: cada turma abrigava, em média, de 48 a 55 alunos. Tal situação, muitas vezes, dificultava o trabalho dos docentes, visto que nem sempre esses espaços comportavam as carteiras enfileiradas e/ou em círculo, tampouco permitiam uma boa circulação dos presentes.

A questão da superlotação é conexa a outro grande problema existente: a dispersão por parte dos discentes. Era consenso, entre os estagiários de várias licenciaturas e professores, as dificuldades de se ensinar naquela escola ${ }^{3}$. Durante nossa observação nas aulas de Sociologia, constatamos as reclamações que docentes discutiam em outros espaços da escola: salas extremamente cheias, falta de concentração, conversas paralelas, desinteresse discente, dentre outros.

Ainda nesse período, percebemos um grande esforço da professora dessa disciplina para que os estudantes participassem das aulas: ela tentou aulas expositivas, levou atividades prontas para serem respondidas em duplas, recortes de jornais com notícias relacionadas às temáticas que estavam sendo trabalhadas e até filmes, no entanto pouco conseguia chamar a atenção. Tal situação não era uma exclusividade das aulas de Sociologia, mas também perpassava as aulas de História, Geografia e de outras áreas do conhecimento. É necessário frisar que, ao apontar tais questões, não queremos desqualificar as práticas pedagógicas dos professores, mas assinalar os obstáculos enfrentados no exercício da docência.

Foi nesse contexto que observamos as sociabilidades cotidianas e estas nos permitiram compreender o lugar da diferença na escola. Em sala de aula, durante os intervalos, foi possível constatar a existência de um padrão de masculinidade hegemônica entre os estudantes, porém este modelo nem sempre surgia compartilhado por todos. Tal situação nos alertou a refletir acerca das questões relacionadas aos diferentes marcadores sociais que constituem o corpo discentes: como são abordados na e pela escola, visto se tratar de um ambiente composto por grande diversidade.

3 A instituição em que ocorreu a pesquisa situava-se próxima da UFPI. Assim, era corriqueiro que vários discentes dos cursos de licenciatura a procurassem para cumprir o estágio e, desse modo, as dificuldades referentes a essas experiências eram partilhadas. 


\section{O lugar da diferença e da diversidade sexual na escola}

A escola tem sido considerada um espaço privilegiado e uma das molas propulsoras para a compreensão da sociedade. Assim como Semprini (1999), entendemo-la como um espaço destinado à formação do indivíduo, sendo por meio dela que os sujeitos podem transcender seus laços familiares e criar outros sentimentos de pertencimento. A educação, nesse sentido, tem a missão de conduzi-los ao plano do amadurecimento, permitindo-lhes forjar um espírito crítico.

No entanto, para que isso se concretize, é necessário por parte dos professores, além do domínio do arcabouço teórico sobre diversidade, abarcar a compreensão das diferenças em sua materialidade, pois “a diferença não é simplesmente, ou unicamente, um conceito filosófico, uma forma semântica"; ela é "antes de tudo uma realidade concreta, um processo humano e social, que os homens empregam em suas práticas cotidianas e estão inseridas no processo histórico" (Semprini, 1999:11) e que, por isso mesmo, precisam ser reconhecidas e respeitadas.

Apesar da urgência de um debate sobre o reconhecimento, respeito e valorização da diversidade no espaço educativo, aqui no Brasil ainda existem muitas barreiras, fato que nos exige certa parcimônia. Quadros e Nascimento (2015), ao refletirem sobre uma experiência de formação continuada de professores da Educação Básica da rede estadual de Pernambuco, demonstraram que as questóes relacionadas à diversidade, sobretudo, diversidade de gênero e sexo, ainda permanecem marginalizadas. Mesmo com a expansão das políticas públicas que visam a esse reconhecimento, os autores se depararam com relatos que demonstram a impotência da instituição no combate às práticas preconceituosas e de exclusão do diferente vivenciadas na e pela escola. Uma postura semelhante foi percebida em nosso trabalho de campo, durante o qual a equipe docente adotava um comportamento licencioso durante as tensões entrelaçadas de gênero, classe e raça.

Dessa forma, percebemos que uma educação voltada a refletir sobre gênero e sexualidade em uma perspectiva mais ampla é ainda escassamente abordada em contextos escolares e a instituição pesquisada não é exceção. Altmann (2001), ao problematizar a orientação sexual como tema transversal a ser trabalhado em todos os ciclos da Educação Básica, demonstra como tal inserção foi pensada a partir de uma perspectiva biológica do sexo, desde o âmbito da reprodução humana, sendo projetada a partir de uma matriz heterossexual, monogâmica e matrimonial, distante da realidade discente.

A preocupação da escola com a regulação dos corpos e da sexualidade discentes não é uma novidade na educação moderno-ocidental, conforme assinalamos já de início. No contexto brasileiro, Altmann (2001) e Cesar (2009), ao realizarem um resgate histórico de como a educação sexual figurava nos currículos nacionais, demonstram que, durante as décadas de 1920 a 1930, os “desvios sexuais" não eram mais tipificados como crime, contudo, ainda permaneciam vistos como patologias. Os currículos formulados nesse período tinham como principal interesse constituir um "sexo bem educado", respeitando as moralidades heterossexuais e fazendo proliferarem discursos vinculados à higiene e eugênicos de pureza racial.

Sob essa luz, uma das diretrizes da escola seria, portanto, a de transmitir aos jovens os saberes para uma sexualidade sadia. Posteriormente, nas décadas de 1960 a 1970, houve um esforço de movimentos 
feministas para a implementação da educação sexual nas escolas, no entanto terminou suprimido no período ditatorial militar, que guardava em seu bojo uma moralização dos costumes. Na contemporaneidade, a educação sexual possui outra roupagem e um novo discurso produtor de saberes na educação brasileira, colonizada pelas ciências biológicas. Seu principal norteador é a prevenção e conscientização sobre o risco de doenças sexualmente transmissíveis e de gravidez precoce (Altmann, 2001).

$\mathrm{Na}$ escola em que realizamos nosso trabalho de campo, contudo, as questões sobre gênero e sexualidade não estavam presentes nas aulas nem a partir do discurso de matriz biológica. $O$ próprio Projeto Político Pedagógico (PPP) da instituição não fazia qualquer menção a conteúdos que trabalhassem tais temas de forma transversal às disciplinas, conforme a preconização legal. A palavra "sexualidade" sequer aparecia no texto do documento. Nesse cenário, a única referência a essa problemática aparecia na descrição de oficinas artísticas, alertando para a não reprodução de qualquer tipo de discriminação. No documento não existiam informações sobre as oficinas ou como seriam coordenadas ou operacionalizadas na instituição.

Percebemos ainda que o restante do documento se encontrava em sintonia com o cotidiano da escola, apresentando uma série de dados sobre o número de alunos, taxas de aprovação e o crescimento da matrícula. Porém, nenhuma inferência existia quanto ao reconhecimento e o respeito às diversidades, legitimando através da ausência de diretrizes pedagógicas substanciais no PPP as práticas discriminatórias e excludentes. Logo, quando algum estudante demonstrava comportamento dissidente dos padrões de gênero hegemônicos, a instituição parecia ter uma atitude rápida, sendo ela velada ou explícita, de correção das corporalidades dos meninos da escola.

\section{Corporalidades e masculinidades plurais na escola}

O gênero pensado como constructo cultural tem como pressuposto a ideia de que homens e mulheres constroem seu próprio gênero a partir de referências externas, como a família ou os grandes meios de comunicação, também o moldando a partir de uma autonomia própria. Segundo Connell e Pearse (2015:156), "fazemos nosso próprio gênero, mas não somos livres para fazermos como quisermos. Nossa prática de gênero é poderosamente formatada pela ordem de gênero em que nos encontramos".

O conceito de gênero contesta, por conseguinte, a naturalização de um esquema binário de hierarquização do masculino sobre o feminino. Tradicionalmente à figura masculina são atribuídas características que exaltam a racionalidade, a postura ativa e a inserção na esfera pública, enquanto que a figura feminina é tida como emotiva, passiva e pertencente à esfera privada ou doméstica (Giffin, 2005). Ao problematizar tais percepções, os estudos nesse contexto, a princípio, mantiveram em sua maioria um esquema binário nas análises sobre os pressupostos de gênero, afastando, assim, a discussão sobre masculinidades do círculo de estudos feministas. Para Giffin (2005:49):

Nós, feministas, afastamos os homens e criamos espaços públicos exclusivamente femininos, nos quais enfocamos nossa falta de poder nas relações com os homens. [...] Entendo que a obsessão feminista foi produtiva e necessária no sentido de trazer à visibilidade estruturas e relações sistê- 
micas de poder que foram legitimadas pela ciência e naturalizadas nas ideologias de gênero binárias dominantes. Afinal, os estudos de gênero mostraram que tais ideias binárias, expressas em símbolos e normas sociais, estruturaram instituições, foram oficializadas em leis, e encarnaram em identidades pessoais, ou seja, participaram da construção de uma realidade social, são aspectos da nossa realidade social. [...] No entanto, ao representar todos os homens como poderosos e todas as mulheres como oprimidas, estávamos reproduzindo o binarismo.

Considerado esse panorama, percebe-se que a emergência dos estudos acerca da produção de masculinidades surge como um "reflexo da 'crise' imposta à identidade masculina dos anos 60, oriundo da segunda vaga feminista e da emergência do movimento homossexual" (Heilborn \& Carrara, 1998:2). É preciso frisar que o campo dos estudos de masculinidades não é sinônimo da produção positivista do conhecimento que toma o homem como sujeito universal ou, como apontava a crítica feminista nos anos 70, as "ciências do homem". As pesquisas sobre masculinidades ganhariam mais fôlego a partir da década de 1990, tanto no contexto estadunidense quanto brasileiro ${ }^{4}$. Inclusive, aqui no Brasil, pesquisas sobre relações de gênero, família e sexualidade em interface com masculinidades foram fomentadas nesse período $(i d$.$) .$

Para Connell (1995, 2016), a masculinidade é uma produção social e histórica a partir do encontro dos jovens com um sistema complexo de relações de gênero. As ordens de gênero diferem entre si, e, como resultado, a produção de masculinidades pode ser alterada de acordo com os interesses econômicos e políticos vigentes. Essa autora oferece uma definição sucinta do que entende por masculinidade:

A masculinidade é uma configuração de práticas em torno da posição dos homens na estrutura das relações de gênero. Existe, normalmente, mais de uma configuração desse tipo em qualquer ordem de gênero de uma sociedade. Em reconhecimento desse fato, tornou-se comum falar de masculinidades (Connell, 1995:188).

Kimmel partilha do pensamento de Connell e Messerschmidt (2013), ao postular a masculinidade não somente como um dado cultural entrelaçado com identidade e período histórico, mas, também, como relações de poder. Segundo o autor, no interior dessas relações, encontram-se "desigualdades entre homens e mulheres (de gênero, etnia, idade, sexualidade, etc.)" (Kimmel, 1998: 105). Nesse sentido, os homens podem ser oprimidos pelo mesmo sistema que lhes garante uma série de benefícios dentro do patriarcado.

As relações entre os gêneros não são, dessa forma, embates entre blocos homogêneos. O conceito de masculinidade hegemônica expressa a existência de uma masculinidade subordinada a outra, ou melhor, como grupos específicos de homens são oprimidos dentro das relações patriarcais. Kimmel demonstra como a masculinidade hegemônica dispõe de um discurso que inferioriza outros modelos, ao relatar como o homem branco, anglo-saxão e norte-americano marginalizava homens de origens diferentes:

4 Heilborn e Carrara (1998), Connell (1995) e Giffin (2005) apontam o surgimento de alguns escassos movimentos de homens a refletirem e a desconstruírem os aspectos danosos da masculinidade. 
$\mathrm{Na}$ virada do século [XIX - XX], novos imigrantes europeus também foram somados à lista de outros subalternos. Os irlandeses afirmaram a sua reivindicação de masculinidade tornando-se "brancos" - estes que há muito eram vistos como não sendo uma raça pura na Bretanha [...]. Os Italianos também eram vistos como passionais demais e voláteis para possuírem autocontrole masculino. Os judeus eram demasiadamente almofadinhas, intelectualizados e miúdos para serem homens. Hoje em dia, os asiáticos é que também são vistos como pequenos demais, demasiadamente gentis, moles, sem pelos e afeminados (Kimmel, 1998:115).

Com a colocação de Kimmel, pode-se inferir que a masculinidade não é cristalizada em um binarismo de gênero, mas, sim, intercambiável em um contexto no qual os traços tidos como femininos aparecem em detrimento daqueles masculinos. Para Connell (1995, 2016) e Connell e Pearse (2015), o incentivo ao constructo de uma masculinidade viril e agressiva acarreta sérias consequências, sobretudo, na população jovem. Para a autora, a constante afirmação da própria masculinidade ligada a um comportamento agressivo faz com que os garotos cultivem hábitos danosos à saúde (como o fumo e o uso desenfreado de álcool) e, ainda, se exponham a maiores situações de violência. Diante disso, tomando como referência uma multiplicidade das formas existentes de expressão da masculinidade, bem como a existência de desigualdades nas relações de gênero entre homens face a uma masculinidade hegemônica, tornou-se possível perceber, através do trabalho de campo, os padrões de masculinidade cristalizados e reproduzidos na escola em foco.

O estudante que se mostrava altivo e conciliava a jornada dos estudos com o trabalho, sem demonstrar comportamentos agressivos e/ou violentos no espaço da escola, dificilmente experimentava alguma discriminação ou represália referentes à performance de seu gênero. Em contrapartida, os garotos cujos arranjos de gênero indicavam uma expressão mais sensível e edulcorada de suas masculinidades estavam mais sujeitos à violência, operacionalizada por meio de piadas, chegando à suspensão da escola. Essas ações eram efetuadas principalmente pelo corpo docente e burocrático da instituição. Caso o aluno fosse assumidamente homossexual, o controle sobre sua corporeidade era mais intenso e menos velado, em suma, as opressões se tornavam mais cristalinas.

O constructo da masculinidade era, desse modo, expresso através dos corpos dos alunos, corpos apresentados como produto da cultura, que produz e reproduz discursos. A forma de caminhar, por exemplo, e outras ações cotidianas são construções culturais e variam entre diferentes sociedades. $\mathrm{O}$ corpo na sociedade ocidental foi morosamente deixando de ser visto como universal, ou seja, como se cuidados e investimentos nele acontecessem em sua totalidade. Paulatinamente, o corpo foi sendo fragmentado e anatomizado em diferentes especialidades. Sobretudo na contemporaneidade, o corpo é bricolado e composto por uma gama de signos que, em um primeiro olhar, podem parecer contraditórios e/ou até excludentes (Mauss, 2017; Goellner, 2003; Le Breton, 2016).

A corporalidade aceitável como viril pela escola em análise era expressa por meio do relógio de pulso, das correntes de metal penduradas no pescoço e de um caminhar truncado, arrastado. Bem distante do padrão de masculinidade hegemônica, todavia, também era comum encontrar garotos assumidamente gays, usando batom, acessórios femininos, blusas mais curtas para que a barriga ficasse à mostra ou, ainda, até mesmo performando um “caminhar mais solto" dentro da escola, isto é, meninos 
que construíam e modelavam seus corpos para além de uma matriz e performance heterossexual. Aqueles que assim o desejassem, ostentavam signos que fugiam da masculinidade hegemônica e que não se remetiam a uma dita virilidade (Butler, 2000; Connell \& Pearse, 2015; Connell, 2016).

Durante a sociabilidade com garotos inseridos na masculinidade hegemônica da escola, ficou claro como o gênero estava calcado em valores específicos, tais como liderança e sustento à família. Além do trabalho formal ou informal, a conquista de garotas e, sobretudo, um relacionamento sério eram motivos de orgulho entre os rapazes, pois constituíam marcadores da masculinidade tida como correta, saudável e moralmente superior a outros modelos. Pereira (2014), ao analisar a produção das masculinidades em diferentes contextos envolvendo os marcadores de classe e raça, demonstra como essa construção está articulada com a posição que o jovem ocupa na sociedade de classes. Segundo ela, enquanto os filhos de famílias abastadas eram direcionados, a partir da infância, a terem ocupações de maior prestígio na produção capitalista e/ou herdar os meios de produção de seus ancestrais, os jovens das camadas pobres eram forçados a apostar todas as suas fichas no trabalho formal ou informal, para tentar alcançar prestígio social. Tal situação, a nosso ver, parece se confirmar na realidade da instituição investigada.

Entre os garotos ouvidos, aqueles inseridos no mercado formal geralmente trabalhavam como caixas de supermercado, atendentes de telemarketing ou com algum trabalho braçal. Aqui, é perceptível como gênero, classe e raça se imbricam na construção de um dos vários tipos de masculinidades existentes na sociedade (Scott, 1995; Louro, 2014). No caso da escola estudada, o estudante heterossexual conciliador do trabalho e do estudo, enfrentando uma dupla jornada, era bem-quisto pelos alunos e pelo corpo docente. Os professores não somente (re)produziam esses marcadores constantemente, como também exclamavam isso como motivo de orgulho para os alunos e os generificavam como tais (Connell, 1995; Connell \& Pearse, 2015; Dayrell, 2007).

A despeito da apreciação acima em que foi possível perceber a valoração de uma determinada maneira de se expressar a masculinidade, vamos analisar, a partir de nossa inserção na escola, quatro casos pelos quais foi possível constatar a inexistência de uma masculinidade hegemônica unificada. Nesse sentido, notou-se que mesmo aqueles alunos pertencentes aos padrões esperados carregavam traços subjetivos que os diferenciavam de algum modo, enquanto outros, cujos corpos foram produzidos a partir da norma heterossexual vigente, não tinham problemas em trocar abraços, carícias e brincadeiras com colegas assumidamente gays.

O trabalho de campo revelou, portanto, como as práticas de afeto e tolerância com os estudantes que não atendiam aos arranjos de gênero, de como 'ser masculino', tinham limites que permitiam sua aceitação ou exclusão em certos grupos ou espaços.

\section{Corpos que resistem e a exclusão social}

O corpo se adapta e é moldado a partir do contexto sociocultural. O sujeito cujo corpo se encontra exposto a constrangimentos variados, aprende mecanismos de defesa no cotidiano, tornando, de uma forma geral, a corporalidade passível de tentativas de controle dentro da escola. Na análise a seguir, 
o enfoque será sobre os corpos que exprimem masculinidades tidas como extremas e como práticas de violência ou exclusão são perpetuadas pelos discentes, docentes e atores burocráticos da escola nesse quadro de relações e tensões (Foucault, 2014; Butler, 2000; Le Breton, 2016).

O trabalho de campo tornou possível revelar como a escola lida com as nuances existentes nos padrões de masculinidade dos alunos, com ênfase sobre dois tipos de corporalidades a serem subordinadas, posto que sempre eram tidas como abjetas pela comunidade escolar. A primeira concerne àquela na qual a virilidade é potencializada, ou seja, o corpo atesta sua masculinidade através da violência física ou de atividades ilícitas, dentro e fora da escola. A segunda se refere àquelas masculinidades que subvertem completamente a norma heterossexual, nas quais meninos se permitem usar batom e adereços femininos sem, inicialmente, ter receio de represálias. A partir dos relatos de Bruno, Luigi, Juliano e Umberto $^{5}$, será perceptível verificar como ambos os extremos de corporalidade transparecem as práticas e o discurso normatizador da escola diante de masculinidades a serem subordinadas.

Em campo notou-se que os meninos envolvidos em atividades ilícitas e arriscadas eram enxergados como tendo uma potente virilidade. Aqueles engajados em delitos ou que demonstravam valentia com outros estudantes e professores(as) eram vistos como figuras dotadas de agressividade, incumbindo-se a isso uma narrativa de um poder genuíno dentro do ambiente escolar. Partindo do discurso de uma professora e dos próprios alunos, nos foi revelado como a ostentação de uma alta quantia de dinheiro emergia enquanto um marcador identitário de uma masculinidade ligada à agressividade entre os estudantes. Para os docentes e discentes, um aluno com grande quantidade de dinheiro dentro do espaço escolar (público) estaria automaticamente ligado a atividades criminais (extraclasse).

Uma das professoras relata o caso de Bruno, que havia sido recentemente transferido para outra escola. Durante a conversa, ela destacou como Bruno gostava de abrir a carteira diante de outras pessoas para mostrar "o bolo das notas de cem reais". Além da suspeita do envolvimento com atividades ilícitas, Bruno colecionou denúncias de ameaças contra alunos e alunas que reclamavam sobre ele atrapalhar as atividades em sala. Uma colega de aula relatou que, quando cobrou de Bruno e seus amigos que fizessem silêncio durante uma das aulas, foi respondida com uma ameaça de agressão física. Esse tipo de problema não era restrito somente a Bruno, tanto que a professora contou como a diretora arranjou uma forma de transferir a ele e outros em mesma situação para uma nova escola. Nesse momento, percebe-se que a instituição de ensino prefere se eximir a lidar com o caso, bem como verificam-se as questões sociais que perpassavam a vida desses discentes.

Logo, um dos extremos existentes da masculinidade hegemônica na escola é o garoto tido como perigoso, ou, melhor dizendo, aquele que exerce uma coerção através da agressividade sobre o corpo docente e discente. Os homens também não escapam do peso do machismo, sobretudo, aqueles inseridos em um contexto de periferia da cidade, principalmente os negros e/ou de classes mais baixas. $\mathrm{Na}$ escola estudada, não chega a ser diferente: por mais que os jovens generificados como masculinos tirem proveito de uma hierarquia de gênero que os privilegia, existe um custo a ser pago. Esses alunos têm seus corpos apagados da sociabilidade, sobretudo, porque tendem a valorizar a atividade laboral (ilícita) em detrimento dos estudos, dificultando uma das possíveis saídas dos jovens da periferia da capital 
piauiense, permeados pela condição socioeconômica frágil. No caso específico de Bruno, ao invés da gestão da escola conversar e procurar saber sua realidade, bem como incorporá-la na educação, por não conseguir moldá-lo à sua lógica, acaba por expulsá-lo (Dayrell, 2007).

O corpo, quando se choca intensamente contra a matriz heterossexual, também sofre sanção pela instituição. Desse modo, os meninos cujos corpos são investidos de signos ditos femininos acabam por sofrer punições - em alguns casos, havendo a expulsão de sala de aula ou até mesmo a retaliação física. Luigi, assumidamente homossexual, não tinha vergonha em ostentar uma corporalidade que subvertia completamente o discurso hegemônico sobre as práticas e padrões de masculinidade na escola. Esse aluno mantinha uma postura combativa em sala de aula, além de corporificar sua performance de gênero através de signos usualmente considerados femininos, expressos de diferentes formas: o uso da blusa de uniforme mais curta, fazendo com que a barriga ficasse à mostra, assim como de materiais escolares cor de rosa ou que fugissem do estereótipo de gênero masculino.

Sob o controle parcial discente e docente, o garoto reinventava mecanismos, tendo como vetor o corpo para a afirmação de uma representação de gênero relacionada a práticas de feminilidade, portanto chocando-se com o discurso matriz e hegemônico sobre o que é ser masculino, reforçado constantemente dentro do âmbito escolar (Butler, 2000; Le Breton, 2016). Luigi assumia que, aos sábados, sempre ia a um pagode com "trajes femininos" ${ }^{\text {, }}$, produzindo, assim, seu corpo de modo aceitável naquele espaço, conforme verificamos em seu relato: "Ah, professor... Eu, todo final de semana, vou ao pagode. Eu pego meu cabelo, coloco umas presilhas, passo o batom, boto um shortinho curto e fico 'nos paredões' de som dançando e rebolando".

Ensaiar passos de dança característicos das coreografias de ritmos como pagode e funk, juntamente com meninas que figuravam coleguismo dentro da classe, eram formas de resistência para Luigi. O grupo de meninos que, no momento da pesquisa, se identificava enquanto heterossexual não tinha nenhum problema em abraçar ou deixar Luigi sentar em seus colos em momentos de sociabilidade na escola. Claro que isso não eximia Luigi das piadas sobre sua sexualidade, as quais, na maioria das vezes, eram endossadas e reforçadas por ele próprio. Em um dado momento, Luigi decidiu usar batom. Isso logo após o intervalo, e, então, durante a aula, ele relata: "a diretora disse que eu não posso usar batom porque Deus fez o homem pra mulher e vice-versa!".

O simples uso de um batom fez com que a diretora, cuja orientação era abertamente neopentecostal, usasse de uma justificativa de cunho religioso para repreender o aluno, tornando-o passível de total constrangimento em frente ao corpo discente, sobretudo, de seus colegas. Como resposta, Luigi decidiu passar um brilho labial, buscando evidenciar ainda mais sua boca como forma de protesto.

Em outro momento, Luigi estava ensaiando para uma apresentação de dança junina que seria realizada na escola e, durante essas ocasiões, sempre que possível reproduzia os passos ensinados às garotas, chegando, inclusive, a pedir ao professor para dançar ele próprio os passos femininos. Teve, em seguida, seu pedido negado, pois todos os pares já estavam formados de acordo com o modelo binário de gênero. Os estudos de Melo (2018), Noleto (2018) e Menezes Neto (2019) demonstram que os

6 A escolha da expressão se deve ao fato de que era assim que Luigi denominava seu vestuário, sempre ressaltando a feminilidade de suas roupas. 
festejos juninos, enquanto cultura popular, são terrenos profícuos para colocar em xeque concepções cristalizadas sobre gênero e sexualidade e a participação de corporalidades dissidentes. Todavia, tal participação enfrentou e ainda enfrenta resistência por parte dos organizadores, avaliadores e até da própria comunidade em geral. Essa resistência é justificada como proteção à tradicionalidade dos festejos juninos ${ }^{7}$.

A corporalidade de Luigi, que anteriormente enfrentou a ação punitiva e normalizadora da direção, acabou por ficar em silêncio perante o professor e colegas de classe, pois todos eles lidaram com humor diante da situação constrangedora que terminou por intimidá-lo - foi esta a primeira vez que vimos Luigi, cujo corpo expressava uma performance irradiante e combativa, ser forçado a se calar. Durante essa situação, o professor que estava organizando a quadrilha sugeriu, de forma irônica, que tinha o conhecimento de que Luigi "queria ser uma menina", mas que, naquele momento, não seria possível e ele devia voltar para o seu lugar na quadrilha. A coerção docente foi endossada e reproduzida por uma aluna que ressaltou que Luigi "queria ser mulher de vez".

Diferente dos momentos de sociabilidade nas aulas e no intervalo, a tolerância com a corporalidade e masculinidade não hegemônicas de Luigi foi inexistente. Por ser um evento aberto para toda a comunidade escolar, surge a emergência de um controle mais incisivo do corpo e gênero de Luigi, diferente de quando ele estava em grupos específicos que o aceitavam. Acrescida da jocosidade, vêm a latente discriminação e a exclusão da performance que Luigi gostaria de realizar na festa junina.

Luigi, ao expressar uma masculinidade subversiva ao modelo heterossexual, acaba por ter seu corpo excluído culturalmente, pois se constitui de signos culturalmente ligados ao gênero feminino, portanto, chocando-se com o seu "sexo" preestabelecido e regulado forçosamente pela matriz biológica, sobretudo, a partir da representação social de sua genitália (Louro, 2014). O exemplo da violência sofrida por Luigi demonstra como os arranjos de gênero que a escola, de forma sublime, tenta reproduzir no corpo dos discentes é incompleta. Para além disso, mostra que nem mesmo uma performance tida como exagerada pelos colegas de classe será tolerável em todos os contextos (Butler, 2000). A fala do professor, por fim, demonstra um desconhecimento dos debates tão crescentes sobre a diversidade de gênero na escola e, ademais, acaba reforçando a exclusão e o preconceito vivenciado por Luigi.

Outro exemplo de intolerância e desrespeito com os corpos foi vivenciado por Juliano. Esse aluno do terceiro ano sofreu uma punição pelo simples fato de ousar elaborar uma fabricação de seu corpo. O garoto iria desfilar "montado" em um evento da escola, para tanto, fez-se necessária uma produção corporal completa: maquiagem pesada, vestido rosa choque, peruca e sandália de salto alto. O evento

7 Noleto (2018), em um estudo sobre festejos juninos em Belém (PA), mostra que, apesar das competições permitirem a participação de homens gays e transsexuais, ainda há uma tendência a persistir o que o autor denomina de uma "heterossexualidade e cisgeneridade coreográfica” na reprodução dos papéis de cavalheiros e damas nas competições. Menezes Neto (2019), ao analisar o documentário $O$ São João também étrans, de Thiago Castro, mostra a importância das festas juninas em Sobral (CE) para mulheres transsexuais enquanto espaço de acolhimento e de expressão de suas diversidades. Melo (2018), ao estudar as competiçôes juninas em Recife (PE), articula acontecimentos presenciados em campo que demonstram o leque de formas com que os festejos juninos podem desestabilizar uma concepção binária de gênero. Elencaremos duas situações extremamente ricas exploradas pela autora. A primeira se refere à representação da corporalidade transsexual no circuito competitivo, que acontece tanto de forma cômica caricatural, quanto corporificando o papel da dama, sendo assim uma representação ambivalente, pois ao mesmo tempo que desestabiliza as categorias, existe uma sublime reprodução da cisgeneridade coreográfica. A segunda foi em uma competição em 2013, em que Severino Boca Virgem, o protagonista da apresentação, ao final contrai matrimônio com outro rapaz, ao invés de com uma mulher. A apresentação em questão subverteu completamente a matriz heterossexual. 
em questão era referente a uma atividade cultural que acontecia quinzenalmente na escola, na qual os alunos ficavam depois das aulas escutando música e dançando. Por vezes, diferentes apresentações aconteciam. Nessa quinzena em específico, ficou combinado que Juliano poderia desfilar momentos antes de a música começar a tocar. Como o desfile seria realizado no último horário do turno, o garoto se "montou" na escola durante o intervalo. Contudo, foi impedido de assistir à aula de matemática no horário anterior ao evento, pois o professor não tolerou sua presença enquanto estivesse travestido.

O caso, ao chegar à direção, não foi resolvido. A direção adotou uma postura esquiva, alegando que não poderia fazer nada por Juliano e que ele voltaria a assistir às suas aulas normalmente após o desfile. Para evitar lidar com o conflito, diretora e professores se eximiram do papel de educadores, acabando por não problematizar a situação, bem como corroborando o preconceito do docente - que ministrava a aula de matemática -, impedindo a efetivação de uma educação compromissada com o reconhecimento e respeito às diferenças.

As experiências discriminatórias de Luigi e Juliano guardam uma semelhança: a homossexualidade de ambos era tolerada e parcialmente respeitada quando seus corpos e gêneros estavam, em alguma medida, sincronizados com a matriz heterossexual vigente na escola. Porém, a partir do momento em que essa norma era completamente subvertida pelo desejo de ocupar papéis relacionados ao feminino, rapidamente surgiam à superfície discursos intolerantes.

Já a experiência de Umberto com a postura discriminatória da direção foi descoberta através de um desabafo do próprio aluno ${ }^{8}$. Durante uma das aulas de Sociologia, surgiu um debate sobre preconceito. Nesse momento, foi perguntado aos estudantes quem ali já tinha sofrido preconceito por alguma razão. A posteriori, com o debate construído e embasado por vários exemplos das diferentes formas de discriminação (sobretudo raça e classe), os discentes perguntaram se eu já havia experienciado alguma forma de preconceito. E isso encorajou um contexto oportuno de me colocar na posição de já ter sofrido preconceito na minha vida estudantil, portanto incentivando a outros alunos que falassem sobre suas experiências.

Durante essa aula, Umberto, que estava sentado no fundo, me chamou para comunicar algo. O aluno cochichou em meu ouvido que já havia sofrido preconceito por parte da própria diretora da escola acerca de sua sexualidade. Diante do fato relatado, sugeri que poderíamos conversar sobre o ocorrido em um momento posterior à aula. Então, ele contou:

Professor, teve uma vez, na hora do intervalo, que eu estava de mãos dadas e abraçado com meu ex-namorado, naqueles banquinhos do pátio da escola. Quando a diretora passou pela gente e viu, mandou a gente soltar a mão na hora e disse pra gente não fazer mais aquilo na escola. Na hora, eu fiquei sem reação e acabei soltando a mão. Eu sei que nenhum casal pode ficar se pegando na escola, mas o que a gente estava fazendo era o que os héteros faziam. Andar de mãos dadas e sentar próximo um do outro. E a diretora nunca fala nada deles ou fala mal de nenhum deles. Eu pensei em contar pra minha mãe, porque ela sabe que eu sou gay e que eu namorava esse menino na época, mas como ela [a mãe] é muito barraqueira, fiquei com medo de dar confusão na escola.

$8 \mathrm{O}$ relato aconteceu apenas na presença do segundo autor do artigo, em uma das aulas ministradas durante o estágio. Por isso, nessa passagem está empregada a $1^{\text {a }}$ pessoa do singular. 
O temor de relatar para sua mãe a violência sofrida era plausível, visto que os outros casos de discriminação citados acima não foram solucionados, nem problematizados. Como apontado por Miranda e Maia (2017), situações envolvendo qualquer tipo de violência ou discriminação de gênero na escola são, costumeiramente, confundidas com "problemas de disciplina". Contudo, o caráter preconceituoso da ação da diretora não passou despercebido por Umberto: ele tem consciência de que foi vítima de homofobia. Apesar disso, escolheu não relatar a violência para sua mãe, que tinha conhecimento de sua sexualidade e o aceitava.

O que podemos inferir dessa situação e tomando como base a fala do próprio discente é que, ao denunciar o caso para sua mãe, esta iria tomar satisfação com a escola, o que poderia trazer maiores transtornos para o estudante. Nesse caso, a situação não se resolveria e ele possivelmente poderia sofrer algum tipo de exposição e/ou sanção por parte da gestão institucional. Provavelmente, se a tensão entre Umberto e a direção tivesse inflado, ele acabaria expulso da escola, visto que tal ação parecia ser comum e legitimada no que tange à resolução dos conflitos. É necessário frisar que a aceitação da sexualidade de Umberto por parte da mãe não implica que o namorado desfrute da mesma aceitação, logo é possível que Umberto tenha evitado maiores confrontos para também não expor o rapaz.

Os quatro casos apresentados demonstram a postura punitiva da escola, bem como a reprodução discriminatória no que tange às relações de gênero binárias neste ambiente. A própria diretora, guiada por um ideal neopentecostal, pune as diferentes formas de afeto entre os rapazes ali matriculados, independente da sexualidade e ainda contribui, mesmo que paulatinamente, na construção de uma masculinidade calcada na supressão de sentimentos e na rigidez. Uma ironia, visto que a direção transfere os alunos que são taxados como agressivos e violentos.

Para Butler (2000), quando pessoas se afirmam, de maneira naturalizada, enquanto homens ou mulheres, há uma abjeção de outras formas de vivenciar o gênero. As pessoas consideradas fora de padrão, na maioria das vezes, acabam marginalizadas e mais suscetíveis à violência. Os garotos, por possuírem construções de si fortemente destoantes da masculinidade hegemônica presente na escola, tendem a enfrentar sanções que buscam normatizar seus corpos e identidades de gênero. Os estudantes, em contrapartida, não aceitam de forma passiva as imposições da instituição. O corpo se destaca não apenas por ser um dos principais alvos de regulamentação forçada, mas também como principal ponto de resistência. Contudo, quando os discentes geram atritos em decorrência das tentativas de docilizar seus corpos (seja de forma explícita ou velada) e a regulação não se mostra possível, a equipe docente acaba impedindo o aluno de frequentar a escola.

\section{Considerações finais}

Aqueles corpos que excedem para o extremo em relação ao modelo de masculinidade hegemônica tendem a ser apagados e têm sua educação tolhida e/ou ceifada. Quando as práticas de masculinidade estão em um extremo que privilegia a agressão e a virilidade, os garotos são remanejados e/ ou expulsos da escola. O discurso dos professores e da direção indica que tal medida é necessária para manter a segurança no espaço educacional. 
Em um polo oposto, os alunos que possuem masculinidades permeadas por práticas e/ou traços de feminilidades também sofrem represálias, estas sendo inibidas de suas respectivas performances de gênero entre os meninos. Especialmente se as práticas e/ou traços, por sua vez, estão mais associados à feminilidade que à masculinidade. A incursão na escola evidencia como as punições foram mais severas para Juliano, que, ao se travestir para um evento cultural, foi impedido de assistir à aula.

O mesmo acontece com Luigi, que, ao tentar assumir o papel feminino na dança da festa junina, é imediatamente recolocado em "seu lugar" generificado. Enquanto Umberto fora impedido de desfrutar de uma prática que era exercida por estudantes heterossexuais. Ao contrário da reação indiferente da escola perante a postura carinhosa de Luigi com outros colegas de classe não lidos enquanto gays assumidos, quando se tratou de um casal homoafetivo, caso de Umberto, a direção surgiu com uma série de mecanismos para enquadrar os dois alunos na matriz heterossexual vigente.

Luigi, ao possuir práticas de feminilidade refletidas em seu corpo através do batom ou da blusa, tendeu por sofrer com um discurso que busca masculinizar seu corpo, mas não houve um impedimento de vivenciar a escola (se comparado aos casos de expulsão). Todavia, quando Luigi decide intensificar a sua feminilidade na festa junina, tratam imediatamente de compeli-lo e impedi-lo de dançar como gostaria. No caso de Bruno e Juliano, suas performances de masculinidade abjeta fizeram com que a equipe da escola logo legitimasse o discurso que os excluiria da convivência: quanto a Bruno, a expulsão por seu suposto envolvimento em atividades ilícitas; e, no que tange a Juliano, o banimento da sala de aula por estar travestido em razão de um evento.

O discurso da comunidade escolar como um todo, que exalta a qualidade do jovem capaz de conciliar trabalho e estudo, está ligado ao papel atribuído aos homens como provedores na divisão do trabalho, visto ser o mecanismo considerado lícito para garantir o acesso a melhores condições de vida e bens de consumo (Scott, 1995; Pereira, 2014).

A experiência da observação participante, realizada no estágio, revelou como os corpos de garotos permeados por práticas ditas femininas despertam uma atenção e um interesse naqueles que possuem a intenção de "corrigi-los" e "enquadrá-los" novamente à norma de masculinidade vigente, gerando assim um processo de exclusão dos alunos. Esse processo é reforçado se os discentes se exacerbam em não se encaixarem na norma heterossexual estabelecida. Assim, as tensões de gênero se tornaram cada vez mais evidentes na escola pesquisada, que tendeu a acionar uma série de discursos e mecanismos, visando à homogeneização da masculinidade naquele local.

Naquele contexto, as violências citadas acima, devido aos garotos performarem uma masculinidade abjeta, assumem um papel peculiar. Quando os alunos demonstram alguma tendência mais enfática tida como homossexual ou que exprime de forma assumida a própria homossexualidade, a violência surge como um mecanismo que relembra as normas hegemônicas de gênero. Mas essa tentativa de regular os corpos dissidentes não é exclusiva daqueles que demonstram sinais efeminados.

É praticamente impossível não perceber a forma punitiva com que a escola lidou com Bruno, como um reflexo do que acontece atualmente fora dos muros das instituições de ensino, quando jovens que cometem algum tipo de infração são apenas presos e expelidos de todo e qualquer convívio social (Pascoe, 2018). As experiências vivenciadas durante o período do estágio curricular demonstra- 
ram como a equipe docente da escola apresenta desconhecimento acerca da abordagem das questões relacionadas à diversidade de gênero, classe e raça, discussões estas que são latentes naquele âmbito. Enquanto machismo, fundamentalismo religioso e postura indiferente acabam tornando a educação um meio de exclusão, quando, a priori, sua função deveria ser justamente a oposta.

Basta pensar em Bruno, Juliano, Luigi, Umberto e também em outros jovens que se evadem da escola devido aos discursos de expurgo escutados nesse espaço que deveria ser acolhedor. Quanto mais dissidentes se revelam as práticas de masculinidade dos estudantes em relação ao discurso sobre o ideal hegemônico, piores se mostram as punições escolares (Sales, 2018). Essas nuances, evidenciadas por nosso trabalho de campo, nos parecem de fundamental inserção no crescente debate sobre inclusão de minorias, que vem efervescendo e tensionando as políticas e as práticas educacionais no contexto brasileiro dos últimos anos.

Raimundo Nonato Ferreira do Nascimento é Doutor em Antropologia pela Universidade Federal de Pernambuco (UFPE). Professor vinculado ao Departamento de Ciências Sociais da Universidade Federal do Piaui (UFPI) e do Programa de Pós Graduação em Antropologia da mesma instituição.

\author{
Marcos Paulo Magalhães de Figueiredo é mestrando em Antropologia pela \\ Universidade Federal do Piaui (UFPI).
}

\title{
REFERÊNCIAS
}

Altmann, H. (2001). Orientação sexual nos parâmetros curriculares nacionais. Revista Estudos Feministas, 9(2), 575-585. https://doi.org/10.1590/S0104-026X2001000200014

Altmann, H. (2013). Educação sexual em uma escola: da reprodução à prevenção. Cadernos de pesquisa, 39(136), 175-200. https://doi.org/10.1590/S0100-15742009000100009

Butler, J. (2000). Corpos que pesam: sobre os limites discursivos do 'sexo’. In: G. L. Louro (ed). O corpo educado: pedagogias da sexualidade (pp.151-167). Belo Horizonte: Autêntica.

Cesar, M. R. A. (2009). Gênero, sexualidade e educação: notas para uma "Epistemologia”. Educar em Revista, 35, 37-51. https://doi.org/10.1590/S0104-40602009000300004

Connell, R. (1995). Políticas de masculinidade. Revista Educação \& Realidade, 20(2), 185-206. https://seer.ufrgs.br/educacaoerealidade/article/view/71725

Connell, R. (2016). Crescer como masculino. In: R. Connell (ed). Gênero em termos reais (pp. 137157). São Paulo: nVersos. 
Connell, R \& Messerschmidt, J. W. (2013). Masculinidade Hegemônica: repensando o conceito. Revista Estudos Feministas, 21(1), 241-282. https://doi.org/10.1590/S0104-026X2013000100014

Connell, R \& Pearse, R. (2015). Gênero: uma perspectiva global. São Paulo: nVersos.

Dayrell, J. (2007). A escola faz as juventudes? Reflexões em torno da socialização infantil. Revista Educação e Sociedade, 28(100), 1105-1128. https://doi.org/10.1590/S0101-73302007000300022

Ferraço, C. E. (2007). Pesquisa com cotidiano. Revista Educação e Sociedade, 28(98), 73-95. https:// doi.org/10.1590/S0101-73302007000100005

Foucault, M. (2013). História da sexualidade I: a vontade de saber. $23^{\text {a }}$ ed. Rio de Janeiro: Edições Graal.

Foucault, M. (2014). Vigiar e punir: nascimento da prisão. 43 a ed. Petrópolis: Vozes.

Giffin, K. (2005). A inserção dos homens nos estudos de gênero: contribuições de um sujeito histórico. Revista Ciência e Saúde Coletiva, 10, 47-57. https://www.scielosp.org/article/csc/2005. $\mathrm{v} 10 \mathrm{n} 1 / 47-57 / \mathrm{pt} /$

Goellner, S. V. (2003). A produção cultural do corpo. In: S. V. Goellner, G. Lopes Louro \& J. F. Neckel (eds). Corpo, gênero e sexualidade: um debate contemporâneo na educação (pp. 28-40). Petrópolis: Vozes.

Heilborn, M. L. \& Carrara, S. (1998). Em cena, os homens... . Revista Estudos Feministas, 6(2), 1-5. https://doi.org/10.1590/\%25x

Kimmel, M. S. (1998). A produção simultânea de masculinidades hegemônicas e subalternas. Revista Horizontes Antropológicos, 4(9), 103-117. https://doi.org/10.1590/S0104-71831998000200007

Le Breton, D. (2006). A sociologia do corpo. Petrópolis: Vozes.

Le Breton, D. (2016). Antropologia do Corpo. Petrópolis: Vozes.

Louro, G. L. (2014). Gênero, sexualidade e educação: uma perspectiva pós-estruturalista. Petrópolis: Vozes.

Malinowski, B. (1979). Argonautas do Pacifico Ocidental. São Paulo: Abril Cultural.

Mauss, M. (2017). As técnicas do corpo. In: Sociologia e Antropologia (pp. 421-441). São Paulo: Ubu Editora.

Melo, L. Q. (2018). "Na minha quadrilha só tem gente que brilha”: corporalidades dissidentes e direitos humanos nas quadrilhas juninas do Recife-PE (Dissertação de Mestrado). Universidade Federal de Pernambuco, Recife. https://repositorio.ufpe.br/handle/123456789/30583 
Menezes Neto, H. (2019). O São João também é trans: resenha do filme de Thiago de Castro sobre a experiência das mulheres trans nas quadrilhas juninas de Sobral - CE. Rebeh - Revista Brasileira de Estudos da Homocultura, 2(3), 210-217. https://doi.org/10.31560/2595-3206.2019.7.10118

Miranda, A. P. M., \& Maia, B. (2017). Olhares, xingamentos e agressões físicas: a presença e a (in) visibilidade de conflitos referentes às relações de gênero em escolas públicas do Rio de Janeiro. Horizontes Antropológicos, 49, 177-202. https://doi.org/10.1590/s0104-71832017000300007

Noleto, R. S. (2018). Limites do gênero, fronteiras da sexualidade: heterossexualidade e cisgeneridade na quadra junina em Belém. In: G. Saggese, M. Marini, R. Lorenzo, J. Simões \& C. D. Cancela. (eds). Marcadores sociais da diferença: gênero, sexualidade, raça e classe em perspectiva antropológica (pp. 287-303). São Paulo: Terceiro Nome, Editora Gramma.

Pascoe, C J. (2018). Notas sobre uma sociologia do bullying: homofobia de homens jovens como socialização de gênero. Tradução de T. M. de Souza. Revista Teoria e Cultura, 13(1), 289-303. https:// doi.org/10.34019/2318-101X.2018.v13.12394

Pereira, F. P. (2014). "Seja Homem": produção de masculinidades em contexto patriarcal. Curitiba: CRV.

Quadros, M. T., \& Nascimento, R. N. F. (2015). O diálogo entre Antropologia e Educação: experiências com a diversidade na formação de professores da educação básica. Amazônica: Revista de Antropologia, 7(1), 244-263. http://dx.doi.org/10.18542/amazonica.v7i1.2158

Reyes, M L. (2004). Masculinidades diversas. Revista de Estúdios de Género: La ventana, 2(20), 101 117. http://revistalaventana.cucsh.udg.mx/index.php/LV/article/view/705

Sales, F. W. S. (2018). "Ao nosso ver é a felicidade", "é a liberdade”: binarismo de gênero e heteronormatividade em sociabilidades juvenis numa escola teresinense (Dissertação de Mestrado). Universidade Federal do Piauí, Teresina. https://repositorio.ufpi.br/xmlui/handle/123456789/1305

Scott, J. (1995) Gênero: uma categoria útil de análise histórica. Revista Educação e Realidade, 20(2), 71-99. https://www.seer.ufrgs.br/educacaoerealidade/article/viewFile/71721/40667

Semprini, A. (1999). Multiculturalismo. Bauru: EDUSC.

Stecanela, N. (2009). O cotidiano como fonte de pesquisas nas ciências sociais. Revista Conjectura: filosofia e educação, 14(1), 63-75. http://www.ucs.com.br/etc/revistas/index.php/conjectura/article/ view/4 


\title{
AÇÕES E REAÇÕES DA ESCOLA DIANTE DE MASCULINIDADES HEGEMÔNICAS E NÃO HEGEMÔNICAS: UM OLHAR ANTROPOLÓGICO
}

Resumo: Durante a década de 1990, com o avanço das políticas públicas de inclusão, a escola pública brasileira foi incitada a contemplar em seus conteúdos o debate sobre sexualidade. Contudo, as diferenças de gênero e sexualidade permanecem sendo suprimidas pela escola, seja de forma sublime ou bem explícita. A partir dessa realidade e com base em uma observação participante, o artigo pretende analisar como a escola, em seus discursos normatizadores, contribui com os processos de construção e afirmação das masculinidades hegemônicas, na corporalidade dos estudantes e, consequentemente, em suas identidades. Pretendemos demonstrar como as concepções cristalizadas de uma masculinidade hegemônica produzida na e pela escola destoam da realidade discente, marcada por uma diversidade sexual e de gênero. No trabalho de campo, constatamos dois tipos de masculinidades vistos enquanto ameaça: o estudante extremamente viril e violento e o estudante visto como demasiadamente feminino. Podemos concluir que a pauta do gênero na educação mobiliza as relações de desigualdade e aciona dispositivos de regulação, visando a enquadrar os estudantes em um padrão hegemônico de masculinidade, considerado salutar pela escola.

Palavras-chave: Masculinidades; Corporalidades; Educação e Diversidade; Sexualidade.

\section{SCHOOL ACTIONS AND REACTIONS TO HEGEMONIC AND NON-HEGEMONIC MASCULINITIES: AN ANTHROPOLOGICAL VIEW}

\begin{abstract}
During the 1990s, with the advancement of public inclusion policies, Brazilian public education was urged to include in its contents the debate on sexuality. However, gender and sexuality differences remain hidden by the school, either in a sublime or explicit way. Based on this reality and on participant observation, the article intends to analyze how the school, in its normalizing discourses, contributes to the processes of construction and affirmation of hegemonic masculinities, in the corporality of the students and consequently in their identities. We intend to demonstrate how the crystallized conceptions of hegemonic masculinity produced by the school are different from the reality of the students, marked by sexual and gender diversity. In the fieldwork, we found two types of masculinities seen as a threat: the extremely virile and violent student and the student seen as too feminine. We can conclude that the gender issue in education mobilizes the relations of inequality and activates regulatory devices, in order to place students in a hegemonic pattern of masculinity, considered healthy by the school.
\end{abstract}

Keywords: Masculinities; Corporalities; Education and Diversity; Sexuality.

RECEBIDO: $31 / 05 / 2020$

APROVADO: $19 / 02 / 2021$ 